\title{
Radiation Dose Reduction in Computed Tomography- Guided Lung Interventions using an Iterative Reconstruction Technique
}

\section{CT-gesteuerte Interventionen an der Lunge: Dosisreduktion mithilfe iterativer Rekonstruktionsalgorithmen}

Authors

Affiliations

\author{
D. H. Chang ${ }^{1}$, S. Hiss ${ }^{1}$, D. Mueller ${ }^{2}$, M. Hellmich ${ }^{3}$, J. Borggrefe ${ }^{1}$, A. C. Bunck ${ }^{1}$, D. Maintz ${ }^{1}$, M. Hackenbroch ${ }^{1}$
}

Department of Radiology, University Hospital of Cologne, Germany

Clinical Science, Clinical Science Philips Healthcare GmbH, Munich, Germany

Institute of Medical Statistics, Informatics and Epidemiology, University Hospital of Cologne, Germany

\author{
Key words \\ Q thorax \\ - biopsy \\ - CT \\ - interventional procedures \\ - image manipulation/ \\ reconstruction
}

\section{Zusammenfassung}

$\nabla$

Ziel: Vergleich der Dosis und Bildqualität bei CTgesteuerten Interventionen unter Verwendung eines Standarddosisprotokolls (SDCT) mit gefilterter Rückprojektion (FBP) und eines Niedrigdosisprotokolls (LDCT) mit FBP und iterativer Rekonstruktion (IR).

Material und Methoden: Retrospektiv wurde die Bildqualität und Strahlendosis (Dosislängenprodukt und CTDI) bei 130 Patienten, die sich einer CT-gesteuerten Lungenintervention unterzogen ausgewertet. SDCT wurde bei 65 Patienten mit einer automatischen Dosismodulation und 120 $k V p$, LDCT bei 65 Patienten mit einer fixierten $\mathrm{mAs}$ und $100 \mathrm{kVp}$ durchgeführt. Die Bildqualität wurde objektiv mittels Kontrast-zu-RauschVerhältnis sowie subjektiv anhand einer 4-Punkte-Skala von zwei Radiologen bezüglich Bildrauschen, Schärfe, Artefakte und diagnostische Akzeptanz bewertet.

Ergebnisse: Es gab keine signifikanten Unterschiede bezüglich der diagnostischen Akzeptanz und der Komplikationsrate in beiden Gruppen. Im Vergleich zu SDCT erreichte LDCT eine Dosisreduktion im Median um 68,6\%. Die Implementation der iterativen Rekonstruktion war bezüglich der Rauschunterdrückung und der subjektiven Bildqualität der FBP überlegen. Bezüglich der Aufhärtungsartefakte ergab sich kein Unterschied zwischen beiden Gruppen.

Schlussfolgerung: Das LDCT-Protokoll erzielt eine signifikante Reduktion der Strahlenexposition um mehr als $2 / 3$, während die diagnostische Sicherheit und Präzision beibehalten werden. Die iterative Rekonstruktion ist, aus der Analyse der objektiven und subjektiven Auswertung der Bildqualität zu bevorzugen.

Kernaussagen:

- Niedrigdosisprotokolle (LDCT) sind bei CT-gesteuerten Interventionen an der Lunge bezüg-

\section{Abstract \\ $\nabla$}

Purpose: To compare the radiation doses and image qualities of computed tomography (CT)-guided interventions using a standard-dose CT (SDCT) protocol with filtered back projection and a lowdose CT (LDCT) protocol with both filtered back projection and iterative reconstruction.

Materials and Methods: Image quality and radiation doses (dose-length product and CT dose index) were retrospectively reviewed for 130 patients who underwent CT-guided lung interventions. SDCT at $120 \mathrm{kVp}$ and automatic $\mathrm{mA}$ modulation and LDCT at $100 \mathrm{kVp}$ and a fixed exposure were each performed for 65 patients. Image quality was objectively evaluated as the contrast-to-noise ratio and subjectively by two radiologists for noise impression, sharpness, artifacts and diagnostic acceptability on a four-point scale.

Results: The groups did not significantly differ in terms of diagnostic acceptability and complication rate. LDCT yielded a median $68.6 \%$ reduction in the radiation dose relative to SDCT. In the LDCT group, iterative reconstruction was superior to filtered back projection in terms of noise reduction and subjective image quality. The groups did not differ in terms of beam hardening artifacts.

Conclusion: LDCT was feasible for all procedures and yielded a more than two-thirds reduction in radiation exposure while maintaining overall diagnostic acceptability, safety and precision. The iterative reconstruction algorithm is preferable according to the objective and subjective image quality analyses.

Key Points:

- Implementation of a low-dose computed tomography (LDCT) protocol for lung interventions is feasible and safe.

- LDCT protocols yield a significant reduction (more than 2/3) in radiation exposure. 
lich diagnostischer Akzeptanz, Sicherheit und Präzision gut durchführbar.

- Die Verwendung von LDCT zeigt in unserer Studie eine Reduktion der Strahlendosis um mehr als 2/3 im Vergleich zu einem Standarddosisprotokoll.

- Die Implementation iterativer Rekonstruktionsalgorithmen bei LDCT verbessert die objektive und subjektive Bildqualität.
- Iterative reconstruction algorithms considerably improve the image quality in LDCT protocols.

Citation Format:

- Chang DH, Hiss S, Mueller D et al. Radiation Dose Reduction in Computed Tomography-Guided Lung Interventions using an Iterative Reconstruction Technique. Fortschr Röntgenstr 2015; 187: 906-914

\section{Introduction}

$\nabla$

Computed tomography (CT)-guided lung interventions are widely used for marker implantation before pulmonary lesion radiotherapy and biopsies to obtain specimens from a suspected nodule or mass for histopathological examination. CT-guided lung intervention is particularly the method of choice for peripherally located and small lesions $(<2 \mathrm{~cm})$ or those determined by CT as unlikely to have bronchoscopic access [1]. Together, the need for a planning sequence, multiple scans to hit the target and a control CT to rule out post-intervention complications are responsible for a mean volume CT dose index up to 40-fold higher than that achieved during a diagnostic CT examination [2]. In cases with non-specific or benign findings, such as those involving rheumatoid nodules, granulomatous diseases or infection, repeated follow-up CT examinations are generally required, resulting in a high cumulative radiation dose to the patient $[3,4]$. The clinician may also be exposed to a radiation dose to an extent dependent on the puncture technique used (fluoroscopy-guided vs. single/multislice acquisition mode) $[2,5]$. Therefore, the establishment of low-dose protocols for CT-guided interventions appears to be particularly beneficial for both the patient and medical staff. Several dose-reduction techniques, such as tube current modulation, reduced tube voltage [6] and noise reduction filters [7], have been successfully implemented in various dedicated clinical settings and have been shown to reduce radiation exposure. Particularly, it may be possible to scan in a low-dose mode during interventions because the lung and soft tissue differentiation would remain sufficient for needle guidance. However, further radiation dose reductions are not recommended because of increased image noise and needle artifacts and consequently degraded image quality, mainly due to limitations of the standard filtered back projection reconstruction algorithm currently used in most CT systems. The iterative reconstruction algorithm is an alternative image reconstruction technique [8]. Unlike conventional filtered back projection, which is based on simpler mathematical assumptions of the tomographic imaging system, iterative reconstruction semi-accurately models the CT data collection process to generate a set of synthesized projections. Previous phantom and clinical studies have shown that iterative reconstruction provides diagnostically acceptable low-radiation dose CT images with reduced image noise for low-radiation dose CT compared with the filtered back projection algorithm [9-12]. The aim of this retrospective study was to compare the radiation doses, image quality and safety of CT-guided interventions using a standard dose CT (SDCT) protocol with filtered back projection reconstruction and a low-dose CT (LDCT) protocol with both filtered back projection and iterative reconstruction (iDose level 5).

\section{Materials and Methods}

\section{$\nabla$}

This study was approved by our hospital institutional review board, which waived the requirement for written informed consent because of the retrospective study design.

A total of 130 consecutive patients with indications for chest intervention were retrospectively enrolled in this study. Patients were excluded if they were younger than 18 years old. The upgrade to an iterative reconstruction technique was implemented in our institution in August 2012. Simultaneously, we established an LDCT protocol for lung interventions. A total of 65 patients underwent non-enhanced LDCT of the chest for biopsies of suspicious pulmonary lesions $(n=61)$ and marker implantations in pulmonary lesions before radiotherapy ( $n=4)$ from October 2012 to June 2014. For the control group, data from 65 consecutive patients subjected to non-enhanced SDCT chest scans from January 2010 to December 2011 were reviewed. All patients in the SDCT group underwent biopsy examinations of suspicious pulmonary lesions.

All examinations were performed on a Brilliance iCT 256 scanner (Philips Healthcare, Cleveland, OH, USA). The detector collimation was $2 \times 128 \times 0.625 \mathrm{~mm}$, which created 256 overlapping slices via a dynamic z-flying focal spot for planning and control CT. The pitch was 0.758 and the rotation speed was $0.33 \mathrm{~s}$. A sequential (axial) acquisition mode and collimation of $4 \times 5 \mathrm{~mm}$ were used as the scan protocol for the procedural CT. The 'L' (lung) filter was chosen as a reconstruction kernel. In the SDCT protocol, the dose modulation technique DoseRight, which included Z-DOM (operating in the $z$-direction), was deployed for helical scans, whereas for the procedural CT, a fixed tube current-time product of $50 \mathrm{mAs}$ was used. In SCDT, the planning, procedural and control CT scan tube voltages were $120 \mathrm{kV}_{\mathrm{p}}$. SCDT examinations were reconstructed using only the filtered back projected algorithm because iterative reconstruction was unavailable at that time. For LDCT, a tube voltage of $100 \mathrm{kV}_{\mathrm{p}}$ was used, as well as a fixed tube current-time product determined according to the settings outlined in $\bullet$ Table 1. A noise reduction strength level (iDose level 5) was set for the iterative reconstruction algorithm iDose (Philips Healthcare), which

Table 1 SDCT denotes the standard-dose chest CT, LDCT the low-dose protocol.

Tab. 1 SDCT = Standarddosis Computertomografie, LDCT = Low-doseComputertomografie.

\begin{tabular}{|c|c|c|c|c|}
\hline & $\begin{array}{l}\text { tube vol- } \\
\text { tage (kVp) }\end{array}$ & $\begin{array}{l}\text { tube current- } \\
\text { time product } \\
\text { (mAs), plan- } \\
\text { ning CT }\end{array}$ & $\begin{array}{l}\text { tube current- } \\
\text { time product } \\
\text { (mAs) proce- } \\
\text { dural CT }\end{array}$ & $\begin{array}{l}\text { tube current- } \\
\text { time product } \\
\text { (mAs) control } \mathrm{CT}\end{array}$ \\
\hline $\begin{array}{l}\text { scan } \\
\text { mode }\end{array}$ & & helical & $\begin{array}{l}\text { axial, } \\
\text { sequential }\end{array}$ & helical \\
\hline SDCT & 120 & $\begin{array}{l}\text { variable, Dose- } \\
\text { Right+ Z-DOM }\end{array}$ & fixed 50 & $\begin{array}{l}\text { variable, Dose- } \\
\text { Right+ Z-DOM }\end{array}$ \\
\hline LDCT & 100 & fixed 50 & fixed 50 & fixed 30 \\
\hline
\end{tabular}




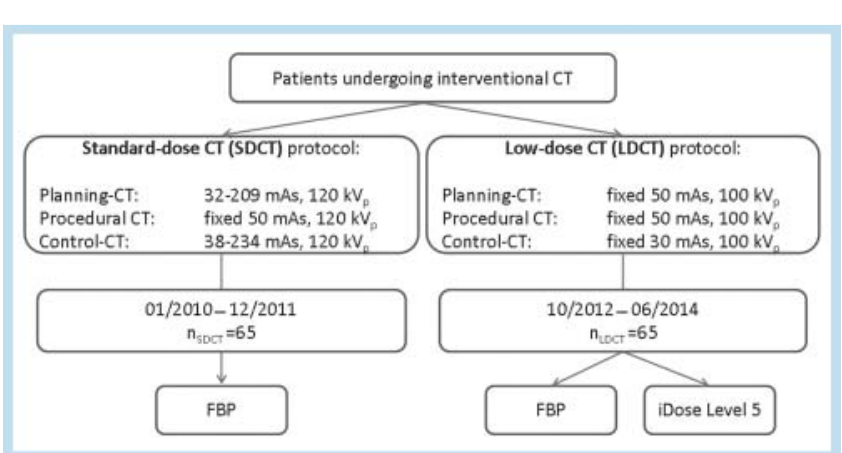

Fig. 1 Study arms; SDCT: variable mAs in Planning and Control CT (range of average mAs for all patients).

Abb. 1 Studienarme; SDCT: variable mAs (Spannweite der mittleren mAs für alle Patienten) für die Planungs- und Kontrollspirale.

was used in the LDCT examinations. LDCT protocol reconstructions (filtered back projection and iDose level 5) were acquired in immediate sequence at the time of the procedure. iDose level 5 reconstruction was performed first and the resulting images were immediately available for the interventional procedure. Meanwhile, filtered back projection was reconstructed in the background and thus did not interfere with the interventions. The study arms are shown in $\bullet$ Fig. 1.

We retrospectively compared the radiation doses as well as subjective and objective image qualities achieved with SDCT and LDCT. The dose-length products and volume CT dose index (mGy) were obtained from the patient dose reports. The effective dose was calculated for all scans according to the dose-length product and an organ-weighting factor for the chest $(k=0.014 \mathrm{mSv} \times(\mathrm{mGy} \times$ $(\mathrm{cm})^{-1}$ ). This factor was averaged between men and women using CT-Expo $[13,14]$.

During the intervention necessary deviations from the standard $\mathrm{mAs}$ value were protocolled. When comparing the two patient groups, important factors that may have influenced radiation doses and image quality were obtained from the radiological information system and patients' charts. The body mass index, intervention time, lesion size and complications were evaluated. Histological findings were listed from the patients' charts.

The time needed for reconstruction, defined as the interval between the end of the scan and image availability on the monitor, was analyzed retrospectively in 52 patients. In the LDCT group, the time(s) for planning and control scan reconstruction with filtered back projection $(n=26)$ and iDose level $5(n=26)$ were measured using a stopwatch. To compare the acquisition times required by the reconstruction algorithms, we calculated the number of images per second (i.e., scan length * (1 image/mm)/acquisition time). Five experienced radiologists ( $>60$ lung interventions each) performed the interventions. A standardized percutaneous biopsy procedure is used at our institution and includes the following steps: first, a limited thoracic CT scan (planning CT, helical acquisition mode) is performed to confirm the nodule location and determine the safest approach. After skin disinfection, a small incision is made at the intended site of biopsy needle insertion. Sequential images (procedural CT, $4.5 \mathrm{~mm}$ collimation) are used to visualize the needle path to the nodule. Specimens are collected using an 18-gauge co-axial biopsy needle (Gallini Medical Devices, Mantova, Italy). A post-procedural thoracic CT scan is subsequently performed (control CT, helical acquisition mode) to rule out complications. Another posteroanterior chest X-ray examination during expiration is performed $4 \mathrm{~h}$ after the intervention. Finally, the patient is discharged from hospital on the following day if no complications occur. The technical aspects of CT-guided marker implantation in malignant pulmonary lesions before radiotherapy do not differ from those of percutaneous biopsy. However, a marker is placed in the lesion before removing the needle, instead of specimen collection. An additional post-procedural chest $\mathrm{CT}$ scan is performed to rule out complications and confirm correct marker positioning.

Complications were categorized using the definitions of the Society of Interventional Radiology (SIR) [15].

\section{Qualitative analysis \\ $\nabla$}

Post-processing and image review were performed on a Picture Archiving and Communication System (Agfa Technical Imaging Systems, Richfield Park, NJ, USA). For image analysis, 585 scans (195 SDCT data sets with filtered back projection and 390 LDCT data sets with filtered back projection and iDose level5) were rendered anonymous with the scan parameters hidden, and the different reconstructions were evaluated side by side in a random order using one series at a time. Two consultant radiologists with 7 and 11 years of experience in diagnostic/interventional CT separately performed the subjective image quality analysis to determine the inter-observer variability. These readers were blinded to patient names, dates of intervention, histological findings, treated complications and information regarding whether filtered back projection or iDose level 5 was used for reconstruction. All data sets were reviewed using lung window settings ( window width $=1300 \mathrm{HU}$; window center $=-500 \mathrm{HU}$ ). The readers were allowed to zoom in and out and to change the window level and width.

The image quality was subjectively assessed for noise impression, vessel sharpness (in the smallest vessel within $1 \mathrm{~cm}$ of the pleural surface) and diagnostic acceptability for the SDCT and LDCT planning scans (filtered back projection and iDose 5) according to a four-point Likert scale as follows: noise impression: $1=$ minimal, $2=$ moderate, $3=$ high without impairment of diagnostic confidence and $4=$ high with impairment of diagnostic confidence; vessel sharpness: $1=$ excellent, $2=$ good, $3=$ fair and $4=$ poor and diagnostic acceptability: $1=$ excellent, $2=$ good, $3=$ fair and $4=$ poor.

In addition the conspicuity of the lesion in the planning and procedural scans (four-point scale, 1 =excellent, 2 =good, 3 =fair and $4=$ poor) and confidence levels for the probe representativeness in procedural scans (three-point scale: $1=$ yes, $2=$ no and $3=$ doubtful) were rated.

In the LDCT group beam hardening artifacts caused by the needle were compared in filtered back projection and iDose 5 procedural scan reconstructions $(1=i$ Dose fewer artifacts than FBP, $2=$ iDose and FBP same number of artifacts, $3=$ iDose more artifacts than FBP).

\section{Quantitative analysis \\ $\nabla$}

Image quality was evaluated objectively as the contrast-to-noise ratio (contrast in $\mathrm{HU}$ defined by the two tissues, divided by the standard deviation of the reference tissue) for all SDCT control scans (filtered back projection) and for LDCT control scans with filtered back projection and iDose. Circular regions of interest 
(ROIs) with an area of $150 \mathrm{~mm}^{2}$ were drawn at the same levels of the aortic arch and lung parenchyma (reference tissue) for all scans. To avoid spurious variations in ROI noise levels within these structures, the ROI position was selected locally according to the minimum noise value.

\section{Statistical analysis \\ $\nabla$}

The chosen sample size of 65 patients per group (LDCT and SDCT) was sufficient to detect a standardized effect of 0.5 ('medium' according to Cohen's categorization) with a power of $80 \%$ and type-I error of $5 \%$ (two-sided $t$-test). Quantitative variables were summarized either as means \pm standard deviations or medians (interquartile ranges) depending on distributional shape. Qualitative variables were described as counts (percentage). Between-group differences in qualitative variables (i.e., frequencies) were evaluated using Fisher's exact test. Between-group differences in quantitative variables were assessed using the Welch-modified t-test or Wilcoxon rank sum test. Note that for location-shifted data, the Wilcoxon rank-sum test evaluates the equality of the corresponding medians. Moreover, radiation dose comparisons (dose-length product and effective dose) were adjusted for age, body mass index and scan length via multivariable linear regression on log scale. Dose data were initially log-transformed to remove apparent right-skewness. Subjective image quality was summarized as a relative frequency and compared between raters. Given the high rating percentages in single categories, the kappa statistics were mostly non-positive and therefore are not given. Statistical significance was assumed for $\mathrm{p}$-values $\leq 0.05$. All calculations were made using SPSS statistical software (Version 22, IBM Corp., Armonk, NY, USA).

\section{Results}

\section{Patient distribution, procedural differences}

and histological findings

Regarding patient distribution, no significant differences in height and gender were observed within the LDCT and SDCT groups. On average, patients investigated using SDCT (38 men and 27 women; age range: 25 - 87 years; mean age: 56 years) were 6.5 years older and approximately $7.3 \mathrm{~kg}$ heavier than those subjected to LDCT (36 men and 29 women; age range: 50 - 84 years; mean age: 63 ).

There were no significant differences in the intervention time and punctured lesion size between the groups. The lesion sizes ranged from 0.4 to $29.9 \mathrm{~cm}^{2}$ in the LDCT group and 0.5 to $27.5 \mathrm{~cm}^{2}$ in the SDCT group $(p=0.054)$.

The mean reconstruction speeds during the planning scans were $15.1 \pm 0.4 \mathrm{~mm} / \mathrm{s}$ for iDose and $20.8 \pm 0.9 \mathrm{~mm} / \mathrm{s}$ for filtered back projection $(n=26)$. For control scans, the reconstruction speeds were $15.2 \pm 0.4 \mathrm{~mm} / \mathrm{s}$ for iDose and $21.1 \pm 0.4 \mathrm{~mm} / \mathrm{s}$ for filtered back projection. Depending on the scan length, the mean waiting times during the planning scans were $11.0 \pm 5.2 \mathrm{~s}$ for iDose and 7.9 $\pm 3.7 \mathrm{~s}$ for filtered back projection. For the control scans, the waiting times were $18.8 \pm 4.5 \mathrm{~s}$ for iDose and $13.6 \pm 3.3 \mathrm{~s}$ for filtered back projection. Regarding complications, we registered 15 cases of pneumothorax $(23.1 \%$ ) in the LDCT group (four cases required additional drainage, complication $C$ according to SIR classification) and 18 cases (27.7\%) in the SDCT group (two cases required additional drainage and minor hospitalization $(<48 \mathrm{~h}$ ), complication $\mathrm{C}$ according to SIR classification; one case required additional drainage and prolonged hospitalization ( $>48 \mathrm{~h}$ ); complication D according to SIR classification). All cases of pneumothorax were initially observed in the post-interventional control scan. Two of seven cases were drained immediately; the remaining five were drained after size progression determined on the X-ray control.

Small, focal parenchymal bleeding areas were observed on the control CT scans of all patients after biopsy in the CT control scan. These required no treatment (complication A according to SIR classification).

Among the collected specimens, malignancy was histologically confirmed in 58 of 61 cases (95.1\%) in the LDCT group and 60 of 65 cases $(92.3 \%)$ in the SDCT group. Three of eight patients (37.5\%) with benign specimens exhibited inconspicuous clinical and radiological (CT examination) findings between 12 and 19 months after the intervention. Five patients were lost to followup. In addition, four markers were successfully implanted before cyberknife radiotherapy in the LDCT group. $\bullet$ Table 2 summarizes the data from both groups.

\begin{tabular}{|c|c|c|c|}
\hline & LDCT $(n=65)$ & SDCT $(n=65)$ & p-value \\
\hline patient distribution & $\begin{array}{l}\text { mean } \pm S D \text {, median } \\
(I Q R) \text { count }(\%)\end{array}$ & $\begin{array}{l}\text { mean } \pm S D, \text { median } \\
(I Q R) \text { count }(\%)\end{array}$ & \\
\hline age (y) & $62.9 \pm 10.7$ & $56.4 \pm 13.8$ & 0.004 \\
\hline gender (male) & $36(55.4 \%)$ & $38(58.5 \%)$ & 0.860 \\
\hline height (cm) & $170.9 \pm 7.6$ & $172.1 \pm 8.5$ & 0.404 \\
\hline weight (kg) & $71.5 \pm 13.2$ & $78.8 \pm 19.1$ & 0.013 \\
\hline BMI (kg/m2) & $24.5 \pm 4.5$ & $26.5 \pm 5.6$ & 0.026 \\
\hline \multicolumn{4}{|l|}{ procedural differences } \\
\hline intervention time ( $\mathrm{min})$ & $28.3 \pm 7.6$ & $27.7 \pm 7.2$ & 0.654 \\
\hline size of punctured lesion $\left(\mathrm{cm}^{2}\right)$ & $3.3(0.4$ to 29.9$)$ & $4.4(0.5$ to 27.5$)$ & 0.054 \\
\hline number of shots during procedure & $6(5$ to 7$)$ & $6(5$ to 7$)$ & 0.955 \\
\hline pneumothorax (n) & $15(23.1 \%)$ & $18(27.7 \%)$ & 0.687 \\
\hline SIR classification: B (n) & 11 & 15 & \\
\hline SIR classification: C ( $n$ ) & 4 & 2 & \\
\hline SIR classification: D (n) & 0 & 1 & \\
\hline histopathological finding & & & 0.140 \\
\hline malignancy (n) & $58(89.2 \%)$ & $60(92.3 \%)$ & \\
\hline nonspecific/indeterminate & $3(4.6 \%)$ & $5(7.7 \%)$ & \\
\hline not applicable (other indication) & $4(6.2 \%)$ & $0(0.0 \%)$ & \\
\hline
\end{tabular}

Table 2 Patient distribution, procedural differences and histological findings in LDCT versus SDCT.

Tab. 2 Patientencharakteristika, prozedurale Unterschiede und histologische Diagnosen der beiden Gruppen (LDCT vs. SDCT). 


\section{Radiation dose}

The median values and interquartile ranges of the planning scan length were $146 \mathrm{~mm}(97-201 \mathrm{~mm})$ in the LDCT group and $201 \mathrm{~mm}(176-255 \mathrm{~mm})$ in the SDCT group $(\mathrm{p}<0.001)$. The median values and interquartile ranges of the control scan length were $290 \mathrm{~mm}(257-331)$ in the LDCT group and $241 \mathrm{~mm}(173-294)$ in the SDCT group $(\mathrm{p}<0.001)$.

The dose-length product values for the planning CT, procedural $\mathrm{CT}$, control CT and the total using both the SDCT and LDCT protocols are shown in units of $\mathrm{mGy} \cdot \mathrm{cm}$ and are expressed as medians (interquartile ranges) in $\bullet$ Fig. 2 and $\bullet$ Table 3. In relative terms, LDCT yielded a $68.6 \%$ reduction in the total dose-length product
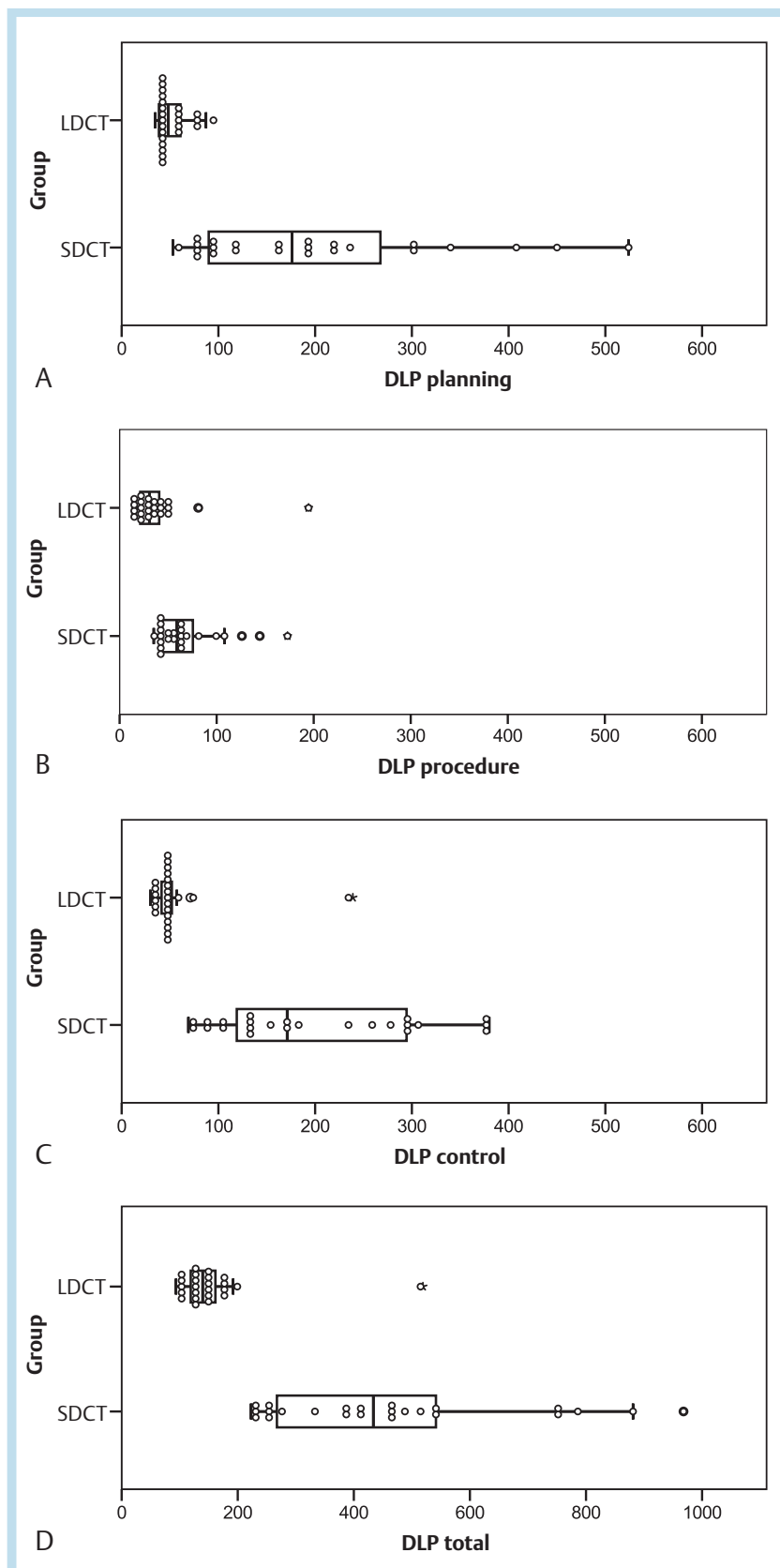

Fig. 2 Dose Length Product (DLP; in units of $\mathrm{mGy} \cdot \mathrm{cm}$ ) in LDCT and SDCT group.

Abb. 2 Dosislängenprodukt (DLP; $\mathrm{mGy} \cdot \mathrm{cm}$ ) in der LDCT- und SDCTGruppe. relative to SDCT ( $\mathrm{p}<0.001)$. After adjusting for age, body mass index and scan length, LDCT yielded a $64.1 \%$ reduction in the doselength product $(\mathrm{p}<0.001)$.

The effective dose (in units of $\mathrm{mSv}$ ) and volume CT dose index (in units of $\mathrm{mGy}$ ) for the planning $\mathrm{CT}$, procedural $\mathrm{CT}$, control $\mathrm{CT}$ and total using both the SDCT and LDCT protocols are expressed as medians (interquartile ranges) and adjusted means (effective doses), respectively, in $\bullet$ Table 4, 5.

\section{Objective image quality analysis}

The contrast-to-noise values (HU units) for the control CT (expressed as medians [interquartile ranges]) for SDCT with filtered back projection and for LDCT with both filtered back projection and iDose 5 were 30.8 (25.0-41.0), $15.4(11.8-18.6)$ and $26.7(21.8-30.0)$, respectively. In relative terms, within the LDCT protocol, use of iDose level 5 yielded a $73.1 \%$ improvement in the contrast-to-noise ratio relative to filtered back projection.

\section{Subjective image quality analysis}

The subjective image quality (i.e., image noise, vessel sharpness, diagnostic acceptability and lesion conspicuity) with iDose 5 always received higher ratings than that achieved with filtered back projection for all criteria and from both readers, as shown in 0 Table 6. However, comparisons regarding location shift (i. e., distribution of ratings) did not reach statistical significance in 4 of 12 comparisons (criteria/readers).

In detail, the difference was not significant for one reader regarding diagnostic acceptability $(\mathrm{p}=0.125)$ and lesion conspicuity $(\mathrm{p}=0.5)$ in procedural CT scans. Furthermore, the difference in lesion conspicuity in the planning CT was not statistically significant for both readers (reader $1: \mathrm{p}=0.25$; reader 2 : $\mathrm{p}=0.063$ ).

In the SDCT group, both readers doubted the representation of one probe because the needle was positioned at the margin of the targeted lesion. The histopathological examination was nonspecific in this case. Also, in the LDCT group, one probe was rated as doubtful, although in this case, the histopathological examination revealed an adenocarcinoma. None of the interventions were rated as 'not representative' regarding the location of the needle. In one case, the tube current-time product was increased, and an additional helical scan was performed in LDCT during the procedure to determine the precise location of the implanted marker.

In all cases subjected to LDCT, needle-induced beam hardening artifacts due to the needle were rated similarly regardless of whether iDose 5 or filtered back projection was used [ $\bullet$ Fig. 3].

\section{Discussion \\ $\nabla$}

CT-guided interventions are an established, routine clinical procedure [16]. The need to reduce radiation exposure derives from the relatively high cumulative dose to the patient [2 - 4]. Furthermore, medical staff may also be exposed to a considerable amount of scatter radiation while standing next to patients during interventions [16 - 19]. Rathmann et al. analyzed the absolute radiation dose values received by medical staff during a total of 131 CT-guided interventions using thermoluminescent dosimetry data [18]. The authors concluded that radiologists had a low overall level of whole-body radiation exposure (mean: $0.022 \mathrm{mSv}$ per procedure; max: $0.164 \mathrm{mSv}$ ). However, a few outlying dose measurements of up to $12.6 \mathrm{mSv}$ for the right hand indicated that significant exposure to the hands should be consid- 
Table 3 Radiation dose DLP (mGy cm).

Tab. 3 Dosislängenprodukt (mGy $\mathrm{cm}$ ).

\begin{tabular}{|c|c|c|c|c|}
\hline & $\begin{array}{l}\text { DLP (mGy cm) } \\
\text { median (IQR) } \\
\text { adjusted mean }(95 \% \mathrm{Cl})^{1} \\
\text { planning CT }\end{array}$ & $\begin{array}{l}\text { DLP }(\mathrm{mGy} \mathrm{cm}) \\
\text { median }(\mathrm{IQR}) \\
\text { adjusted mean }(95 \% \mathrm{Cl})^{1} \\
\text { procedural } \mathrm{CT}\end{array}$ & $\begin{array}{l}\mathrm{DLP}(\mathrm{mGy} \mathrm{cm}) \\
\text { median (IQR) } \\
\text { adjusted mean }(95 \% \mathrm{Cl})^{1} \\
\text { control CT }\end{array}$ & $\begin{array}{l}\text { DLP }(\mathrm{mGy} \mathrm{cm}) \\
\text { median }(\mathrm{IQR}) \\
\text { adjusted mean }(95 \% \mathrm{Cl})^{1} \\
\text { total }\end{array}$ \\
\hline \multirow[t]{2}{*}{ SDCT } & $180(95-299)$ & $57(44-82)$ & $170(121-297)$ & $412(270-539)$ \\
\hline & $144(131-158)$ & $65(58-73)$ & $178(162-196)$ & $401(368-437)$ \\
\hline \multirow[t]{2}{*}{ LDCT } & $49(39-59)$ & $29(20-41)$ & $47(43-52)$ & $129(118-151)$ \\
\hline & $58(53-64)$ & $30(26-33)$ & $46(42-51)$ & $144(132-157)$ \\
\hline \multirow[t]{2}{*}{$p$ - value ${ }^{1}$} & $<0.001$ & $<0.001$ & $<0.001$ & $<0.001$ \\
\hline & $<0.001$ & $<0.001$ & $<0.001$ & $<0.001$ \\
\hline
\end{tabular}

$\mathrm{IQR}=$ interquartile range.

$\mathrm{IQR}=$ Interquartilsabstand.

${ }^{1}$ Adjusted for age, body mass index and scan length by multivariable linear regression on log scale.

Table 4 Effective radiation dose (mSv).

Tab. 4 Effektive Dosis (mSv).

\begin{tabular}{|c|c|c|c|c|}
\hline & $\begin{array}{l}\text { effective dose (mSv) } \\
\text { median (IQR) } \\
\text { adjusted mean }(95 \% \mathrm{Cl})^{1} \\
\text { planning CT }\end{array}$ & $\begin{array}{l}\text { effective dose (mSv) } \\
\text { median (IQR) } \\
\text { adjusted mean }(95 \% \mathrm{Cl})^{1} \\
\text { procedural CT }\end{array}$ & $\begin{array}{l}\text { effective dose (mSv) } \\
\text { median (IQR) } \\
\text { adjusted mean }(95 \% \mathrm{Cl})^{1} \\
\text { control CT }\end{array}$ & $\begin{array}{l}\text { effective dose (mSv) } \\
\text { median (IQR) } \\
\text { adjusted mean }(95 \% \mathrm{Cl})^{1} \\
\text { total }\end{array}$ \\
\hline \multirow[t]{2}{*}{ SDCT } & $2.8(1.7-4.2)$ & $1.0(0.8-1.3)$ & $2.4(1.8-4.3)$ & $6.5(5.2-9.3)$ \\
\hline & $2.4(2.2-2.7)$ & $1.0(0.9-1.2)$ & $2.9(2.6-3.3)$ & $6.7(6.1-7.3)$ \\
\hline \multirow[t]{2}{*}{ LDCT } & $0.9(0.8-1.2)$ & $0.5(0.4-0.7)$ & $0.9(0.7-1.1)$ & $2.5(2.1-2.8)$ \\
\hline & $1.1(1.0-1.2)$ & $0.5(0.5-0.6)$ & $0.8(0.8-0.9)$ & $2.5(2.3-2.8)$ \\
\hline \multirow[t]{2}{*}{ p-value ${ }^{1}$} & $<0.001$ & $<0.001$ & $<0.001$ & $<0.001$ \\
\hline & $<0.001$ & $<0.001$ & $<0.001$ & $<0.001$ \\
\hline
\end{tabular}

$\mathrm{IQR}=$ interquartile range.

$\mathrm{IQR}=$ Interquartilsabstand.

${ }^{1}$ Adjusted for age, body mass index and scan length by multivariable linear regression on log scale.

Table 5 Radiation Dose CTDIvol (mGy).

Tab. 5 Volumenbezogener CT-Dosisindex (mGy).

\begin{tabular}{|llll} 
& $\begin{array}{l}\text { CTDIvol (mGy) } \\
\text { median (IQR) } \\
\text { planning CT }\end{array}$ & $\begin{array}{l}\text { CTDlvol (mGy) } \\
\text { median (IQR) } \\
\text { procedural CT }\end{array}$ & $\begin{array}{l}\text { CTDlvol (mGy) } \\
\text { median (IQR) } \\
\text { control CT }\end{array}$ \\
\hline SDCT & $6.9(3.5$ to 9.9$)$ & $4.4(4.4$ to 4.4$)$ & $6.2(3.5$ to 8.7$)$ \\
\hline LDCT & $2.0(2.0$ to 2.2$)$ & $1.7(1.7$ to 1.7$)$ & $1.2(1.2$ to 1.2$)$ \\
\hline relative reduction & $71 \%$ & $61 \%$ & $81 \%$ \\
\hline p-value & $<0.001$ & $<0.001$ & $<0.001$
\end{tabular}

$\mathrm{IQR}=$ interquartile range.

$\mathrm{IQR}=$ Interquartilsabstand.

ered. In situations where radiologists perform a large number of angiographic and CT-guided interventions, the occupational annual dose limits $(500 \mathrm{mSv}$ for extremities, $20 \mathrm{mSv}$ for the eye lens; 2013/59/EURATOM) may thus be exceeded [20, 21].

At our institution, previous thoracic interventions using an SDCT protocol were found to cause relatively low radiation exposure levels during control scans of the whole thorax (median doselength product: $170.2 \mathrm{mGy} \cdot \mathrm{cm}$ ) compared with a dose reference value published by the German Federal Office for Radiation Protection for diagnostic thoracic CT examinations. In that 2010 publication, the third quartile boundary was defined as 400 $\mathrm{mGy} \cdot \mathrm{cm}$ [5]. Our data have documented a further median control
CT dose reduction of $72.2 \%(47.4 \mathrm{mGy} \cdot \mathrm{cm})$ relative to SDCT. This reduction was achieved using a low-dose protocol with a tube voltage of $100 \mathrm{kV}_{\mathrm{p}}$ and a decreased fixed tube current-time product. A median dose reduction of $68.6 \%$ was obtained for the whole intervention.

Beam energy or X-ray exposure reduction throughout the intervention appears viable, but extensive dose reduction increases the image noise, which can impair successful intervention. Iterative reconstruction algorithms have been shown to maintain image quality through noise reduction despite a decreased radiation dose in chest CT examinations [22]. Higher iterative reconstruction algorithm levels were shown to be preferable [23-25]. Implementation of the iterative reconstruction algorithm iDose in LDCT scans yielded significant improvements in both subjective and objective image qualities. Within the LDCT sample of the present study, a substantial increase in the contrast-to-noise ratio $(73.1 \%)$ was observed for images reconstructed with iDose 5 vs. those reconstructed using filtered back projection ( $\bullet$ Fig. 3 ). The overall diagnostic acceptability and lesion conspicuity with LDCT were rated as excellent by two readers. LDCT was even feasible in obese patients with body mass index values as high as 31 (mean $\pm \mathrm{SD}=24.5 \pm 4.5$ ). Regarding the subjective image quality criteria, we assume that the superiority of iDose 5 did not reach statistical significance in all instances because of an investigational power insufficiency (i.e., small sample size). However, 
Table 6 Evaluation of subjective image quality by 2 readers (4-point scale).

Tab. 6 Evaluation der subjektiven Bildqualität durch 2 Auswerter (4-Punkt-Skala).

\begin{tabular}{|c|c|c|c|c|c|c|c|c|c|c|c|c|}
\hline & \multirow[b]{2}{*}{ reader } & \multicolumn{5}{|c|}{$\begin{array}{l}\text { low-dose CT } \\
\text { FBP } \\
\text { percentage }(n=65)\end{array}$} & \multicolumn{6}{|c|}{$\begin{array}{l}\text { low-dose CT } \\
\text { iDose } 5 \\
\text { percentage }(n=65)\end{array}$} \\
\hline & & 1 & 2 & 3 & 4 & $\begin{array}{l}\text { median } \\
\text { (IQR) }\end{array}$ & 1 & 2 & 3 & 4 & $\begin{array}{l}\text { median } \\
(\mathrm{IQR})\end{array}$ & p-value \\
\hline \multirow[t]{2}{*}{ noise impression (planning CT) } & 1 & 0 & 51 & 49 & 0 & $2(2$ to 3$)$ & 58 & 37 & 5 & 0 & 1 (1 to 2$)$ & $<0.001$ \\
\hline & 2 & 0 & 28 & 71 & 2 & $3(2$ to 3$)$ & 78 & 20 & 2 & 0 & $1(1$ to 1$)$ & $<0.001$ \\
\hline \multirow[t]{2}{*}{ vessel sharpness (planning CT) } & 1 & 0 & 52 & 42 & 6 & $2(2$ to 3$)$ & 9 & 60 & 31 & 0 & $2(2$ to 3$)$ & $<0.001$ \\
\hline & 2 & 5 & 43 & 48 & 5 & 3 (2 to 3$)$ & 28 & 63 & 9 & 0 & $2(1$ to 2$)$ & $<0.001$ \\
\hline \multirow[t]{2}{*}{ diagnostic acceptability (procedural CT) } & 1 & 69 & 25 & 6 & 0 & 1 ( 1 to 2$)$ & 71 & 28 & 2 & 0 & $1(1$ to 2$)$ & 0.125 \\
\hline & 2 & 54 & 45 & 2 & 0 & $1(1$ to 2$)$ & 77 & 22 & 2 & 0 & $1(1$ to 1$)$ & $<0.001$ \\
\hline \multirow[t]{2}{*}{ diagnostic acceptability (control CT) } & 1 & 75 & 20 & 5 & 0 & $1(1$ to 1$)$ & 95 & 0 & 5 & 0 & 1 (1 to 1$)$ & $<0.001$ \\
\hline & 2 & 40 & 48 & 12 & 0 & $2(1$ to 2$)$ & 52 & 45 & 3 & 0 & 1 (1 to 2$)$ & 0.001 \\
\hline \multirow[t]{2}{*}{ lesion conspicuity (planning CT) } & 1 & 77 & 18 & 5 & 0 & 1 (1 to 1$)$ & 77 & 23 & 0 & 0 & $1(1$ to 1$)$ & 0.250 \\
\hline & 2 & 88 & 12 & 0 & 0 & 1 (1 to 1$)$ & 95 & 5 & 0 & 0 & 1 ( 1 to 1$)$ & 0.063 \\
\hline \multirow[t]{2}{*}{ lesion conspicuity (procedural CT) } & 1 & 58 & 32 & 9 & 0 & 1 (1 to 2$)$ & 68 & 28 & 5 & 0 & 1 (1 to 2$)$ & 0.004 \\
\hline & 2 & 92 & 8 & 0 & 0 & $1(1$ to 1$)$ & 95 & 5 & 0 & 0 & $1(1$ to 1$)$ & 0.500 \\
\hline
\end{tabular}

$I Q R=$ interquartile range; Noise impression ( 1 = minimal, 2 = moderate, 3 = high, without impairment of diagnostic confidence, $4=$ high, with impairment of diagnostic confidence), sharpness of vessels ( 1 = excellent, 2 = good, 3 = fair, 4 = poor), diagnostic acceptability ( 1 = excellent, 2 = good, $3=$ fair, $4=$ poor $)$, conspicuity of the lesion in the beginning and during the intervention ( $1=$ excellent, 2 = good, $3=$ fair, $4=$ poor $)$.

$\mathrm{IQR}=$ Interquartilsabstand; Bildrauschen ( 1 = minimal, 2 = mäßig, 3 = ausgeprägt, ohne Einschränkung der Diagnosesicherheit 4 = ausgeprägt, mit Einschränkung der Diagnosesicherheit), Gefäßschärfe ( 1 = exzellent, 2 = gut, 3 = befriedigend, 4 = mangelhaft), Diagnostische Sicherheit (Ausschluss Komplikationen) während der Intervention und in der Abschlusskontrolle ( 1 = exzellent, 2 = gut, 3 = befriedigend, 4 = mangelhaft), Sichtbarkeit der Läsion am Anfang und während der Intervention ( 1 = exzellent, 2 = gut, 3 = befriedigend, $4=$ mangelhaft).

${ }^{1}$ From Wilcoxon signed-rank test.
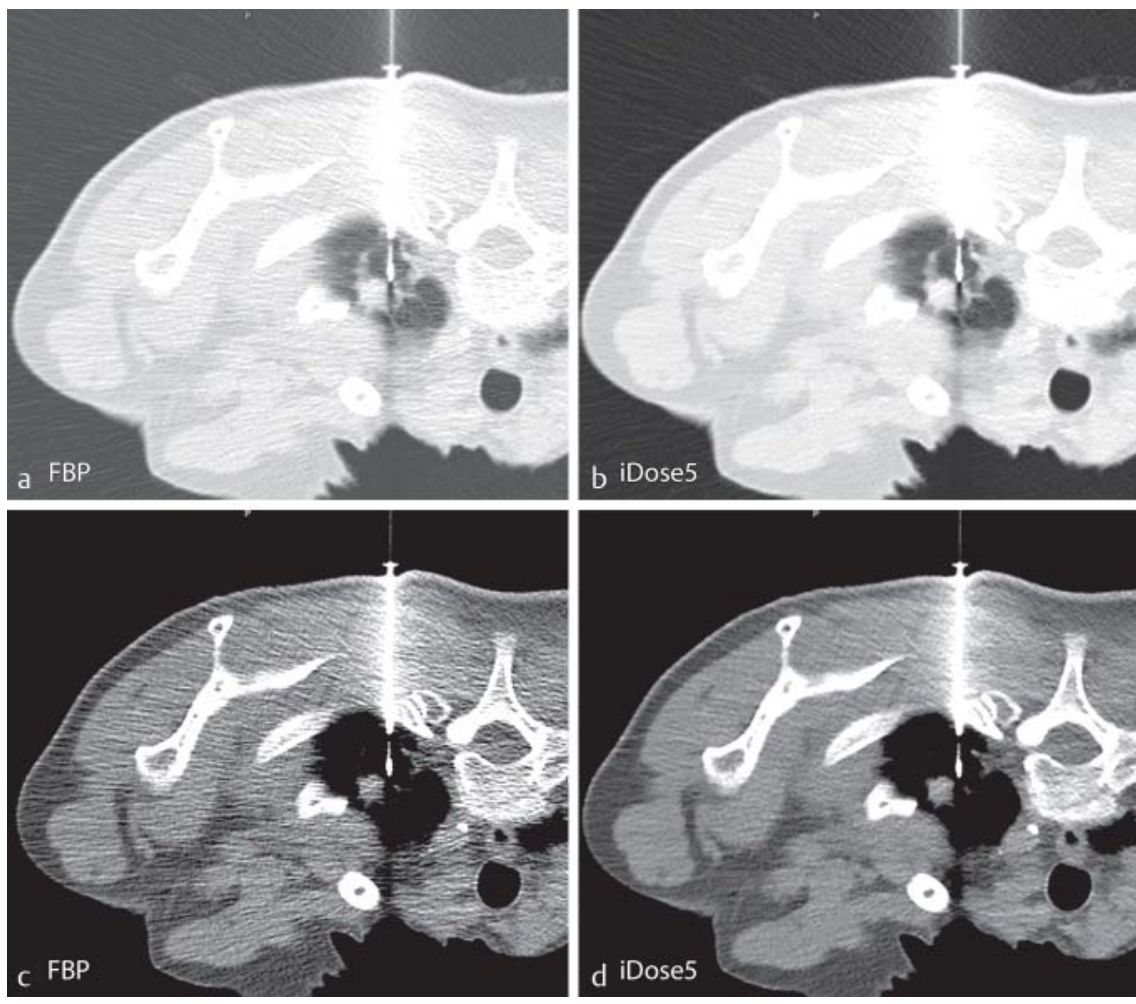

Fig. 3 a-d: 67-year old, obese female (body mass index: 29 ) referred for $\mathrm{CT}$ guided puncture of a suspicious nodule of $12 \times 14 \mathrm{~mm}$ in the right upper lobe. The procedural LDCT images obtained with $100 \mathrm{KV}$; $50 \mathrm{mAs}$ were reconstructed with a, c FBP and $\mathbf{b}, \mathbf{d}$ iDose level 5 . With iDose, image noise was remarkably reduced (CNR a: 18.1, CNR b: 27.2), but needle artifacts were rated same.

Abb. 3 a-d: 67-jährige, adipöse Patientin (BMI: 29) zur CT-gesteuerten Biopsie eines suspekten Rundherds $(12 \times 14 \mathrm{~mm})$ im apikalen rechten Oberlappen. Das LDCT Protokoll (100 KV; $50 \mathrm{mAs}$ ) für die Prozedur wurde rekonstruiert mit a, c FBP und $\mathbf{b}, \mathbf{d}$ iDose level 5. Mit iDose konnte eine deutliche Reduktion des Bildrauschens erzielt werden (CNR a: 18.1, CNR b: 27.2). Es zeigt sich allerdings kein Unterschied in den Nadelartefakten. note that for all criteria, iDose 5 received better scores than filtered back projection.

Regarding the procedural safety, the complication rate observed in our study was in accordance with the literature, wherein pneumothorax occurred in $26-54 \%$ of cutting needle biopsies, of which $3.3-15 \%$ required a chest drain [1].
According to the manufacturer's specifications and the user's hardware capacity, the reconstruction speeds are $33 \mathrm{~mm} / \mathrm{s}$ with filtered back projection and $24 \mathrm{~mm} / \mathrm{s}$ with iDose. We subsequently abrogated the reconstruction time in 52 patients. According to both the manufacturer's and our institutional specifications, filtered back projection reduces the reconstruction time by ap- 
proximately $30 \%$ relative to iDose. In absolute terms, this may be of lesser importance, as the average difference in waiting time for a control scan was 5 seconds ( $18.8 \pm 4.5 \mathrm{~s}$ for iDose and $13.6 \pm 3.3 \mathrm{~s}$ for filtered back projection). Furthermore, in terms of patient safety, the reconstruction speed is considerably more important during the procedure itself than during the planning or control scan. As only four images are needed per procedural scan, the waiting time is in the range of millliseconds. These findings are supported by the fact that there was no significant difference in the overall intervention time between the two groups $(p=0.654)$. The histological findings showed high frequencies of malignancy in both the LDCT (95\%) and SDCT groups (92\%), indicating correct needle placement. In addition, four markers were successfully implanted before cyberknife radiotherapy in the LDCT group. In LDCT, no difference in needle-induced beam hardening artifacts was observed between iDose and filtered back projection. Application of our results to the clinical routine indicates that the implementation of a lung intervention LDCT protocol is feasible and safe. The use of iDose in LDCT protocols considerably improved the image quality by increasing the contrast-to-noise- ratio at a $68.6 \%$ lower radiation dose. According to the ALARA principle, in which radiation dose should be 'as low as reasonably achievable' to complete the procedure successfully, the implementation of iterative reconstruction techniques in CT-guided interventions appears to be reasonable. The excellent overall quality of our image data suggests the further potential for dose reduction using iDose in forthcoming studies.

The following limitations of the study must be mentioned. To compare the radiation dose reduction, an inter-individual comparison was performed between two groups classified according to LDCT vs. SDCT acquisition. It would be desirable to apply both dose protocols in the same individuals. However, this approach cannot be ethically justified. Additionally, patients in the SDCT group were significantly heavier on average than those in the LDCT group, which may have contributed to the relatively higher measured radiation dose in the SDCT group. Furthermore, on average, in the SDCT group, the scan length was longer for the planning scan and shorter for the control scans relative to the LDCT. Variable planning scan lengths are commonly due to patient size, targeted lesion localization and operator preferences. Differences in the control CT are related to the fact that in some SDCT cases $(n=6)$, the interventionalist decided to scan part of the thorax rather than the whole region. This factor may also affect the comparability of the radiation doses in both groups. We therefore repeated the dose-length product and effective dose calculations by adjusting the two groups according to age, body mass index and scan length through a log-scale multivariable linear regression. Additionally we added volume CT dose index, an independent parameter representative of standardized conditions. All results indicated a significant dose reduction with the LDCT protocol $(\mathrm{p}<0.001)$.

\section{Conclusion}

\section{$\nabla$}

The LDCT protocol was feasible in all procedures and even in obese patients. This protocol yielded a significant reduction (more than $2 / 3$ ) in radiation exposure while maintaining overall diagnostic acceptability, safety and precision. iDose level 5 was superior to filtered back projection in terms of both objective and subjective image qualities.

\section{Clinical Relevance of the Study}

- Implementation of a low-dose computed tomography (LDCT) protocol for lung interventions is feasible and safe.

- LDCT protocols yield a significant reduction (more than 2/3) in radiation exposure.

- Iterative reconstruction algorithms considerably improve the image quality in LDCT protocols.

\section{References}

1 Manhire A, Charig M, Clelland C et al. Guidelines for radiologically guided lung biopsy. Thorax 2003; 58: 920-936

2 Prosch $H$, Stadler A, Schilling $M$ et al. CT fluoroscopy-guided vs. multislice CT biopsy mode-guided lung biopsies: accuracy, complications and radiation dose. Eur J Radiol 2012; 81: 1029-1033

3 Inui N, Chida K, Suda T et al. Pulmonary cryptococcosis exhibiting diffuse multiple nodular shadows. Nihon Kokyuki Gakkai Zasshi 1998; 36: $1038-1042$

4 Yeow KM, Tsay PK, Cheung YC et al. Factors affecting diagnostic accuracy of CT-guided coaxial cutting needle lung biopsy: retrospective analysis of 631 procedures. J Vasc Intervent Radiol 2003; 14: 581 - 588

5 Noßke D. Publication of updated diagnostic reference levels for diagnostic and interventional X-ray examinations. German Federal Gazette 2010, Available via http://www.bfs.de/de/ion/medizin/referenzwerte02.pdf

6 Heyer CM, Mohr PS, Lemburg SP et al. Image quality and radiation exposure at pulmonary CT angiography with $100-$ or $120-\mathrm{kVp}$ protocol: Prospective randomized study. Radiology 2007; 245: 577-583

7 Kalra MK, Maher MM, Sahani DV et al. Low-dose CT of the abdomen: Evaluation of image improvement with use of noise reduction filters pilot study. Radiology 2003; 228: 251-256

8 Katsura M, Matsuda I, Akahane $M$ et al. Model-based iterative reconstruction technique for radiation dose reduction in chest CT: comparison with the adaptive statistical iterative reconstruction technique. Eur Radiol 2012; 22: 1613-1623

9 Ohno Y, Takenaka D, Kanda T et al. Adaptive Iterative Dose Reduction Using 3D Processing for Reduced- and Low-Dose Pulmonary CT: Comparison With Standard-Dose CT for Image Noise Reduction and Radiological Findings. Am J Roentgenol 2012; 199: W477-W485

10 Leipsic J, Labounty TM, Heilbron B et al. Adaptive statistical iterative reconstruction: Assessment of image noise and image quality in coronary CT angiography. Am J Roentgenol 2010; 195: 649-654

11 Leipsic J, Nguyen G, Brown J et al. A prospective evaluation of dose reduction and image quality in chest $\mathrm{CT}$ using adaptive statistical iterative reconstruction. Am J Roentgenol 2010; 195: 1095-1099

12 Prakash P, Kalra MK, Digumarthy SR et al. Radiation dose reduction with chest computed tomography using adaptive statistical iterative reconstruction technique: Initial experience. J Comput Assist Tomogr 2010; 34: $40-45$

13 Stamm G, Nagel HD. CT-Expo - a Novel Program for Dose Evaluation in CT. Fortschr Röntgenstr 2002; 174: 1570 - 1576

14 American Association of Physicists in Medicine (AAPM). The measurement, reporting, and management of radiation dose in CT: report of AAPM Task Group 23 of the Diagnostic Imaging Council CT Committee-January 2008. College Park MD: AAPM, 2007: AAPM report no. 96

15 Sacks D, McClenny TE, Cardella JF et al. Society of Interventional Radiology clinical practice guidelines. J Vasc Interv Radiol 2003; 9 Pt 2: $199-202$

16 Hausler U, Czarwinski R, Brix G et al. Radiation exposure of medical staff from interventional $\mathrm{x}$-ray procedures: a multicentre study. Eur Radiol 2009; 19: 2000-2008

17 Buls N, Pagés J, de Mey J et al. Evaluation of patient and staff doses during various CT fluoroscopy guided interventions. Health Phys 2003; 85: $165-173$

18 Rathmann N, Haeusler U, Diezler P et al. Evaluation of Radiation Exposure of Medical Staff During CT-Guided Interventions. J Am Coll Radiol 2015; $12: 82-89$

19 Teeuwisse WM, Geleijns J, Broerse JJ et al. Patient and staff dose during CT guided biopsy, drainage and coagulation. Br J Radiol 2001; 74: $720-726$ 
20 Whitby M, Martin CJ. A study of the distribution of dose across the hands of interventional radiologists and cardiologists. Br J Radiol 2005; 78: 219-229

21 Burgess AE, Burhenne HJ. Finger doses in special procedures. Br J Radiol 1984; 57: 650-651

22 Singh S, Kalra MK, Gilman MD et al. Adaptive statistical iterative reconstruction technique for radiation dose reduction in chest CT: A pilot study. Radiology 2011; 259: 565-573

23 Higuchi K, Nagao M, Matsuo Y et al. Detection of ground-glass opacities by use of hybrid iterative reconstruction (iDose) and low-dose 256- section computed tomography: a phantom study. Radiol Phys Technol 2013; 6: 299-304

24 Willemink MJ, Borstlap J, Takx RA et al. The effects of computed tomography with iterative reconstruction on solid pulmonary nodule volume quantification. PLoS One 2013; DOI: 10.1371/journal.pone.0058053

25 Hosch W, Stiller W, Mueller D et al. Reduction of radiation exposure and improvement of image quality with BMI-adapted prospective cardiac computed tomography and iterative reconstruction. Eur J Radiol 2012; 81: $3568-3576$ 